\title{
Newborns discriminate novel from harmonic sounds: a study using magnetoencephalography
}

Citation for published version (APA):

Sambeth, A., Huotilainen, M., Kushnerenko, E., Fellman, V., \& Pihko, E. (2006). Newborns discriminate novel from harmonic sounds: a study using magnetoencephalography. Clinical Neurophysiology, 117, 496-503. https://doi.org/10.1016/j.clinph.2005.11.008

Document status and date:

Published: 01/01/2006

DOI:

10.1016/j.clinph.2005.11.008

Document Version:

Publisher's PDF, also known as Version of record

Document license:

Taverne

Please check the document version of this publication:

- A submitted manuscript is the version of the article upon submission and before peer-review. There can be important differences between the submitted version and the official published version of record.

People interested in the research are advised to contact the author for the final version of the publication, or visit the DOI to the publisher's website.

- The final author version and the galley proof are versions of the publication after peer review.

- The final published version features the final layout of the paper including the volume, issue and page numbers.

Link to publication

\footnotetext{
General rights rights.

- You may freely distribute the URL identifying the publication in the public portal. please follow below link for the End User Agreement:

www.umlib.nl/taverne-license

Take down policy

If you believe that this document breaches copyright please contact us at:

repository@maastrichtuniversity.nl

providing details and we will investigate your claim.
}

Copyright and moral rights for the publications made accessible in the public portal are retained by the authors and/or other copyright owners and it is a condition of accessing publications that users recognise and abide by the legal requirements associated with these

- Users may download and print one copy of any publication from the public portal for the purpose of private study or research.

- You may not further distribute the material or use it for any profit-making activity or commercial gain

If the publication is distributed under the terms of Article $25 \mathrm{fa}$ of the Dutch Copyright Act, indicated by the "Taverne" license above, 


\title{
Newborns discriminate novel from harmonic sounds: A study using magnetoencephalography
}

\author{
Anke Sambeth $^{\text {a,b,c, } *}$, Minna Huotilainen ${ }^{\text {a,b,d }}$, Elena Kushnerenko a,b,e,f, \\ Vineta Fellman ${ }^{\mathrm{g}, \mathrm{h}}$, Elina Pihko ${ }^{\mathrm{b}, \mathrm{i}}$

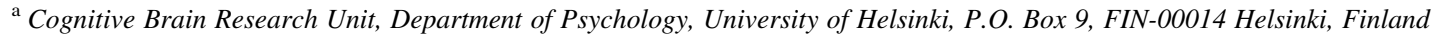 \\ ${ }^{\mathrm{b}}$ Helsinki Brain Research Centre, Helsinki, Finland \\ ${ }^{\mathrm{c}}$ Nijmegen Institute for Cognition and Information, Radboud University Nijmegen, Nijmegen, The Netherlands \\ ${ }^{\mathrm{d}}$ Helsinki Collegium for Advanced Studies, University of Helsinki, Helsinki, Finland \\ ${ }^{\mathrm{e}}$ Department of Human Communication Science, Centre for Developmental Language Disorders and Cognitive Neuroscience, \\ University College London, London, UK \\ ${ }^{\mathrm{f}}$ Centre for Brain and Cognitive Development, School of Psychology, Birkbeck College, London, UK \\ ${ }^{\mathrm{g}}$ Hospital for Children and Adolescents, Helsinki University Central Hospital, Helsinki, Finland \\ ${ }^{\mathrm{h}}$ Department of Pediatrics, Lund University, Lund, Sweden

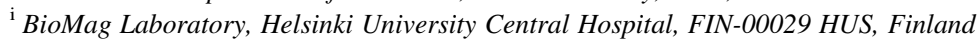

Accepted 12 November 2005

Available online 19 January 2006

\begin{abstract}
Objective: We investigated whether newborns respond differently to novel and deviant sounds during quiet sleep.

Methods: Twelve healthy neonates were presented with a three-stimulus oddball paradigm, consisting of frequent standard (76\%), infrequent deviant (12\%), and infrequent novel stimuli (12\%). The standards and deviants were counterbalanced between the newborns and consisted of 500 and $750 \mathrm{~Hz}$ tones with two upper harmonics. The novel stimuli contained animal, human, and mechanical sounds. All stimuli had a duration of $300 \mathrm{~ms}$ and the stimulus onset asynchrony was $1 \mathrm{~s}$. Evoked magnetic responses during quiet sleep were recorded and averaged offline.

Results: Two deflections peaking at 345 and $615 \mathrm{~ms}$ after stimulus onset were observed in the evoked responses of most of the newborns. The first deflection was larger to novel and deviant stimuli than to the standard and, furthermore, larger to novel than to deviant stimuli. The second deflection was larger to novel and deviant stimuli than to standards, but did not differ between the novels and deviants.

Conclusions: The two deflections found in the present study reflect different mechanisms of auditory change detection and discriminative processes.

Significance: The early brain indicators of novelty detection may be crucial in assessing the normal and abnormal cortical function in newborns. Further, studying evoked magnetic fields to complex auditory stimulation in healthy newborns is needed for studying the newborns at-risk for cognitive or language problems.

(C) 2005 International Federation of Clinical Neurophysiology. Published by Elsevier Ireland Ltd. All rights reserved.
\end{abstract}

Keywords: Auditory; Change detection; Magnetoencephalography; Newborn; Novelty oddball

\footnotetext{
* Corresponding author. Address: Cognitive Brain Research Unit, Department of Psychology, University of Helsinki, P.O. Box 9, FIN00014 Helsinki, Finland. Tel.: +3589 19129451; fax: +358919129450.

E-mail address: anke.sambeth@cbru.helsinki.fi (A. Sambeth).
}

\section{Introduction}

Repetitive auditory stimulation in sleeping human newborns elicits a positive deflection in the event-related potential (ERP), with a latency of about 200-300 ms (Cheour et al., 1998, 2002a; Ellingson et al., 1974; Kurtzberg et al., 1984; Kushnerenko et al., 2002b; Novak 
et al., 1989; Ohlrich and Barnet, 1972). Recently, several studies showed responses at similar latencies (Cheour et al., 2004; Huotilainen et al., 2003; Kujala et al., 2004; Lengle et al., 2001; Pihko et al., 2004) in recordings of evoked magnetic fields (ERFs).

Besides reacting to the repetitive stimulation evoking this basic deflection, newborns can detect changes in otherwise repetitive streams of stimuli, as has been shown frequently using ERPs (e.g. Alho et al., 1990; Kushnerenko et al., 2002a; Martynova et al., 2003) and lately also in ERF studies (Huotilainen et al., 2003; Kujala et al., 2004). This response has been associated with the so-called mismatch negativity (MMN), a pre-attentive change-detection response in adults. The MMN is suggested to be evoked by a comparison process between an irregular, deviant stimulus and a sensory memory trace formed by a standard stimulus (e.g. Näätänen and Winkler, 1999). The MMN component is elicited by any discriminable change in repetitive auditory stimulation. Furthermore, it can be elicited in the absence of attention. In newborns, this change-detection response can be elicited during sleep. For the neonate studies, this is important, since neonates sleep most of the time. In addition, due to e.g. lesser movements, the noise level of electroencephalographic (EEG) and magnetoencephalographic (MEG) recordings of newborns during sleep is significantly smaller than during awake state.

So far, studies on newborns have mostly been carried out with the typical oddball paradigm where the deviants differ from the standard on one aspect, such as pitch or duration, only. It was shown that a mismatch response was elicited both to changes in speech stimuli (e.g. Cheour et al., 2002b; Leppänen et al., 1999) and to changes in pure or complex tones (e.g. Čeponiene et al., 2002; Huotilainen et al., 2003; Leppänen et al., 1997). An oddball paradigm has been used to demonstrate that sleeping newborns are able to learn to discriminate small differences in speech sounds. The MMNlike activity was larger in a group of newborns that had received nocturnal stimulus training than in those that had not (Cheour et al., 2002b).

The change detection response found in newborns does not necessarily have the same potential distribution across the scalp as it does in adults. In adults, the MMN appears strongest at mid-frontal and mid-frontocentral electrodes, and is negative in polarity. In infants, both the polarity and the location of the strongest response have varied across studies (see Friedrich et al., 2004; Leppänen et al., 2004 for a discussion).

The role of the MMN response is proposed to be that of an automatic warning system (Näätänen and Winkler, 1999). Since the warning system is subconsciously monitoring the sound environment and alarming in case of changes, the conscious resources can be saved for other tasks. Possibly due to this important evolutionary role, the MMN has, additionally to the newborn mismatch response, also been observed in monkeys, cats (Csepe et al., 1987), and even in rats (Javitt et al., 1992; Ruusuvirta et al., 1998).
It is proposed that the MMN process triggers the involuntary attention-switching mechanism, manifested in the P3a response (Escera et al., 1998), in order to shift the attention away from the primary task towards the change appearing in the unattended auditory stimulation. Also later processes for reacting and attending to the change may be triggered, which are manifested in children and infants as late deflections found in the responses to the changed sounds, such as the late discriminative negativity (LDN) or late negativity (LN) (Čeponiene et al., 1998, 2002, 2004; Martynova et al., 2003; Shestakova et al., 2003).

The LDN occurs at latencies of 300-750 ms in newborns (Čeponiene et al., 2002; Kushnerenko et al., 2002a; Martynova et al., 2003). The functional significance of this component is still unknown. Further, McIsaac and Polich (1992) have observed a late positive deflection to the deviant stimuli at around 600-900 ms in 6-10-month-old infants. They suggested that this deflection was the equivalent of the adult P3 component. Furthermore, they proposed that this infant ERP component indicates higher cortical functioning in infants. The adult P3 component can be divided into $\mathrm{P} 3 \mathrm{a}$ and $\mathrm{P} 3 \mathrm{~b}$ components. The $\mathrm{P} 3 \mathrm{a}$ reflects an orienting response or novelty detection (Picton, 1992) and can be recorded by both EEG and MEG (Alho et al., 1998), whereas the P3b is said to reflect stimulus evaluation or event categorization (Donchin, 1981; Kok, 2002) and is rarely obtained in MEG studies. The infant P3 component revealed by McIsaac and Polich (1992) mirrored the adult P3a component.

Up to now, it has not been studied within one and the same oddball block in newborns whether attentionattracting novel stimuli elicit stronger responses than the normal deviants, differing from the standard sounds only slightly. Kushnerenko et al., (2002a), however, used two different paradigms, a regular oddball task and a task where the deviant was replaced with so-called novel, attentionattracting stimuli, such as animal and human sounds. In their study, a large positivity, larger than that to the deviants, was found in response to the novel sounds. As did McIsaac and Polich (1992), Kushnerenko with her collaborators suggested that this peak might be an analogue of the adult P3a.

In the present study, we aimed at examining whether newborns respond differently to novels and deviants within a three-stimulus oddball task. Standard and deviant stimuli were 500 and $750 \mathrm{~Hz}$ tones with two upper harmonics and stimuli including human, animal, and mechanical sounds served as novels.

\section{Methods}

\subsection{Subjects}

Auditory magnetic fields were recorded from eleven healthy term newborns (gestational ages 39-42 weeks; 6 
female) at the age of 1-4 days, and in one girl on postnatal day 16 corresponding to a postconceptional age of 39 weeks +2 days. The infants had an Apgar score of 8-9 at $1 \mathrm{~min}$ and a birth weight ranging from 3070 to $3980 \mathrm{~g}$. They were recruited to the study from the maternity ward of Helsinki University Central Hospital. Parental written informed consent was obtained before enrolment. The Ethics Committee of the Hospital District of Helsinki and Uusimaa approved the study plan.

\subsection{Data acquisition}

MEG was recorded using a helmet-shaped Vectorview magnetometer (Elekta Neuromag, Oy, Helsinki) of the BioMag Laboratory, Helsinki University Central Hospital, with 306 channels, in an electromagnetically shielded environment. The channels are located at 102 positions uniformly over the adult head with two orthogonal planar gradiometers and one magnetometer at each location. The measuring helmet was in supine position and the newborn was lying with the right hemisphere over the 'occipital' part of the helmet, enabling the recording of responses of the right hemisphere of the neonates.

Simultaneous EEG and electro-oculographic (EOG) recordings were made with silver-silver chloride disk electrodes to monitor the sleep stages (due to technical problems, the EEG could not be used to calculate ERPs). EEG was recorded at $\mathrm{F} 4, \mathrm{Cz}$, and $\mathrm{P} 4$ locations. EOG was recorded from the upper left and lower right corners of the eyes. The reference electrode was placed on the right mastoid and the ground electrode on the forehead.

Both MEG and EEG were recorded with a band-pass filter of $0.03-200 \mathrm{~Hz}$ and sampled at $600 \mathrm{~Hz}$.

\subsection{Stimuli and procedure}

Stimuli were presented in a three-stimulus oddball condition consisting of standard, deviant, and novel sounds, with all stimulus types present within each sequence. The stimuli were generated using the program 'Adobe Audition' and the experiment was performed using Presentation ${ }^{\circledR}$ software (Version 0.70, www.neuro-bs.com). The standard and deviant stimuli were 500 and $750 \mathrm{~Hz}$ tones with two upper harmonic components (1000 and 1500, 1500 and $2250 \mathrm{~Hz}$, respectively). The intensity of the first and second harmonic components was decreased compared to the fundamental by 3 and $6 \mathrm{~dB}$, respectively. Half the newborns received the $500 \mathrm{~Hz}$ tones as standard, whereas the $750 \mathrm{~Hz}$ tone was used as standard for the other half. Novel stimuli consisted of three stimulus categories of 20 different sounds, namely animal, human, and mechanical sounds. The deviant and novel stimuli were each presented in $12 \%$ of the trials. All sounds had an approximate intensity of $75 \mathrm{~dB}$, a duration of $300 \mathrm{~ms}$ with $10-\mathrm{ms}$ rise and fall times, and were presented with a $1000 \mathrm{~ms}$ stimulus onset asynchrony and equal intensities to the left ear through a plastic tube with a soft earpiece.

The infant was placed in a crib and EEG and EOG electrodes were attached to the skin. A cloth cap was placed over the EEG electrodes and four marker coils were attached for determining the position of the head. The position of the coils in the head coordinate system was determined with an Isotrak 3D digitizer (Polhemus). Thereafter, the newborn infant was placed on a bed next to the MEG helmet in a magnetically shielded room (ETS; Lindgren Euroshield Oy, Eura, Finland). If necessary, the baby was fed before the recording started. The infant's behaviour (eyes open/closed, eye and muscle movements and breathing pattern) was continuously registered by one of the researchers. The recording was started when the newborn was sleeping and the total measurement (preparation and recording) never lasted longer than $2 \mathrm{~h}$.

\subsection{Sleep stage determination}

The sleep stage was determined using the MEG, EEG, EOG, and behavioural measures of the newborns. Active sleep (AS) was characterized by closed eyes, irregular respiration pattern, saccadic eye movements, and occasional facial twitches in the behavioural judgment, by low-voltage high-frequency activity in EEG and MEG, and by sharp eye movements in EOG. Quiet sleep (QS) was characterized by closed eyes and a very regular respiration pattern and either high-voltage low frequency activity or tracé alternants (high and low-voltage slow waves alternating) on EEG and MEG. Responses were averaged according to those sleep stages. Only the responses elicited during the QS will be presented in this paper.

\subsection{Analysis}

Averages for each of the three stimulus types were made offline, according to the sleep stages. Trials during which the neonate moved were rejected. Recordings $(n=11)$ in which the averages in both the deviant and novel condition included at least 100 trials/responses were included in the statistical analysis. The signal space separation method (Taulu et al., 2004) was performed on each of the averages to remove artefacts from outside the helmet (e.g. heart beats and line frequency noise).

Vector sums, calculated from the gradiometer channel pairs using a $40 \mathrm{~Hz}$ low-pass filter, were used for amplitude comparisons of the responses to the three stimulus types. For each infant, a mean of the vector sums from three adjacent channel pairs with the largest responses was used for further analysis. Two deflections were observed in the evoked magnetic responses of the newborns. For each neonate, the peak latency was determined for both deflections and a mean amplitude in a window of 60 and $100 \mathrm{~ms}$ around the peak for the first deflection (named P1m) 
and the second deflection (named $\mathrm{P} 2 \mathrm{~m}$ ), respectively, was used for statistical analysis.

A univariate analysis of variance (ANOVA) with Stimulus Type (standard, deviant, and novel, three levels) as within-subject factor was performed. The Bonferroni

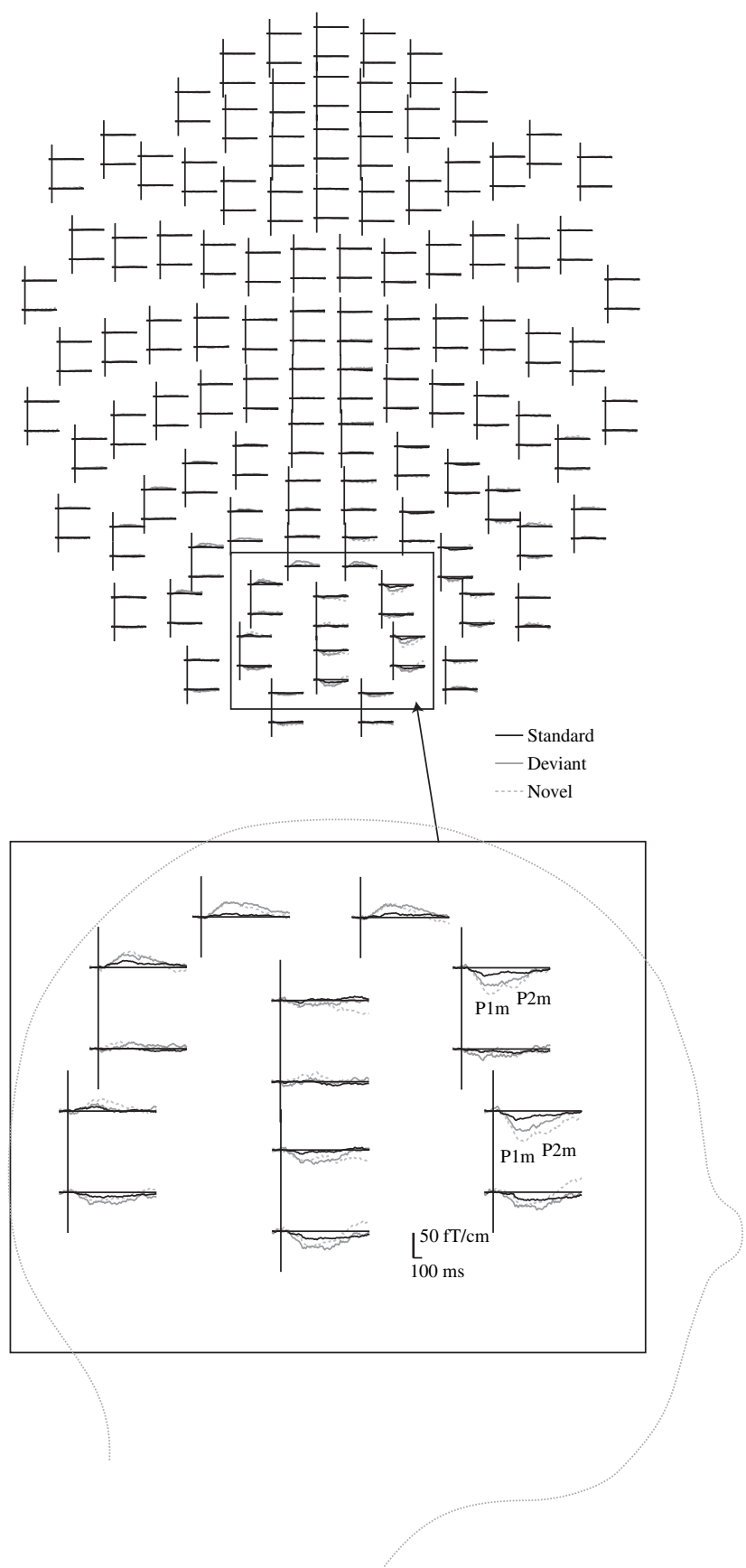

Fig. 1. A grand average over ten newborns during QS. A subset of gradiometer channels from the 'occipital' part of the helmet, on which the infants' heads were laying, is highlighted. Evoked magnetic responses to the three stimulus types, standard (black line), deviant (grey solid line), and novel (grey dotted line) are shown. Two peaks can be determined, pointed out as $\mathrm{P} 1 \mathrm{~m}$ and $\mathrm{P} 2 \mathrm{~m}$. Note, however, that due to the different head positions of the newborns in the measuring device, this grand average does not necessarily show an average of the best channels of each newborn. correction was used for post hoc tests. The level of significance was set at 0.05 throughout.

\section{Results}

Fig. 1 shows a grand average of 10 subjects from all the gradiometer channels. The channels from the occipital part of the helmet, on which the infants' heads were laying, are shown enlarged. Two deflections, pointed out as P1m and P2m, can be seen. Fig. 2 shows responses from one representative newborn (infant 6) during the QS. The same two-peaked pattern can be detected, with latencies of 310 and $600 \mathrm{~ms}$, respectively. Most of the newborns revealed the two-peaked pattern (see Fig. 3, infants 1-7), whereas others (see Fig. 3, infants 8-11) only showed a P1m. The mean latencies of $\mathrm{P} 1 \mathrm{~m}$ and $\mathrm{P} 2 \mathrm{~m}$ over all infants were 345 and $615 \mathrm{~ms}$, respectively.

\subsection{Field distributions}

Fig. 4 shows field distributions during the peaks of P1m and $\mathrm{P} 2 \mathrm{~m}$ for the deviant response in infant 4 and for the novel response in infant 6 . It can be seen from the direction of the arrow, depicting the direction of the neural currents that, in both newborns, the responses recorded with ERPs would appear positive in polarity at the frontal and central electrodes. In general, the field distributions were similar in all newborns except for infant 11 who had the first deflection with an opposite distribution. Therefore, $\mathrm{P} 1 \mathrm{~m}$ of infant 11

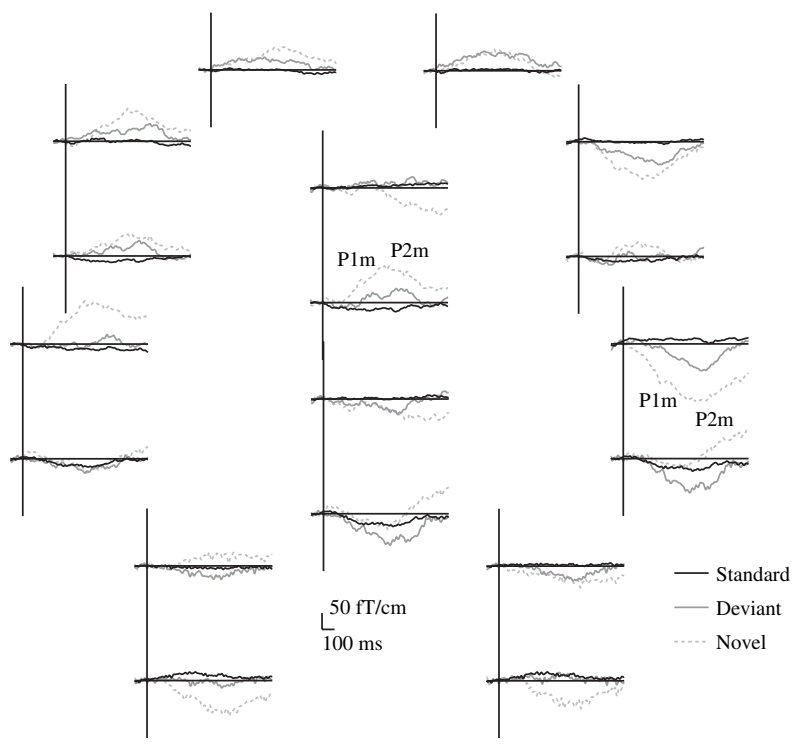

Fig. 2. A subset of gradiometer channels of one representative newborn (infant 6) during QS from the 'occipital' part of the helmet, on which the right hemisphere of this neonate was lying. Evoked magnetic responses to the three stimulus types, standard (black line), deviant (grey solid line), and novel (grey dotted line) are shown. Two peaks can be determined at latencies of 310 and $600 \mathrm{~ms}$ after stimulus onset. 
was excluded from statistical analysis (see Leppänen et al., 2004 for a discussion on the polarity of responses).

\subsection{Stimulus effects}

Fig. 2 shows responses to the standard, deviant, and novel stimuli for eleven newborns during the QS at a representative gradiometer channel. Table 1 gives the mean amplitudes to the three stimulus types for both deflections. The deviant and novel stimuli elicited larger responses than the standard stimulus for both deflections. In most of the infants, the novel elicited larger amplitudes than the deviant, at least for the first deflection.

The ANOVA for P1m revealed a significant effect of Stimulus Type $[F(2,8)=17.81, P<0.001]$. Post hoc evaluation showed that the novel and deviant stimuli elicited larger responses than did the standards $(P<0.01$ for both). The responses to the novel stimuli were larger than those to the deviant stimuli $(P<0.05)$.

An ANOVA for P2m showed an effect of Stimulus Type $[F(2,8)=8.38, P<0.009]$. Post hoc analysis revealed that the novel and deviant stimuli elicited larger amplitudes than did the standard stimuli $(P<0.01$ and 0.05 , respectively), whereas the responses to the novel and deviant stimuli did not significantly differ.

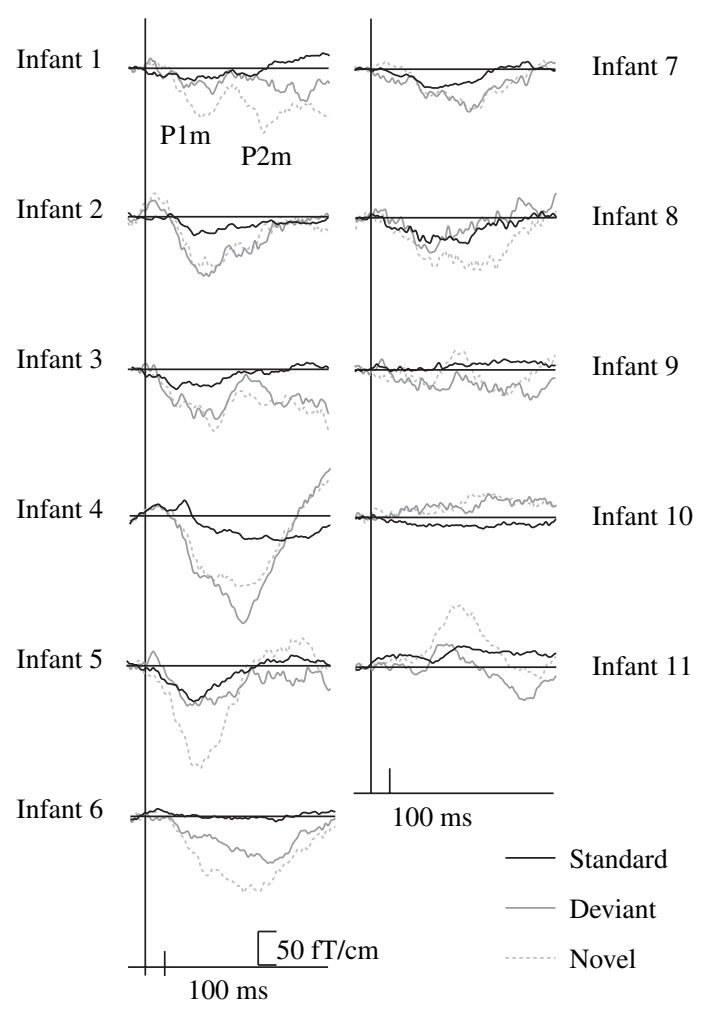

Fig. 3. Evoked magnetic fields of eleven newborns to the three stimulus types standard (black line), deviant (grey solid line), and novel (grey dotted line). For each infant, one representative gradiometer channel is shown.

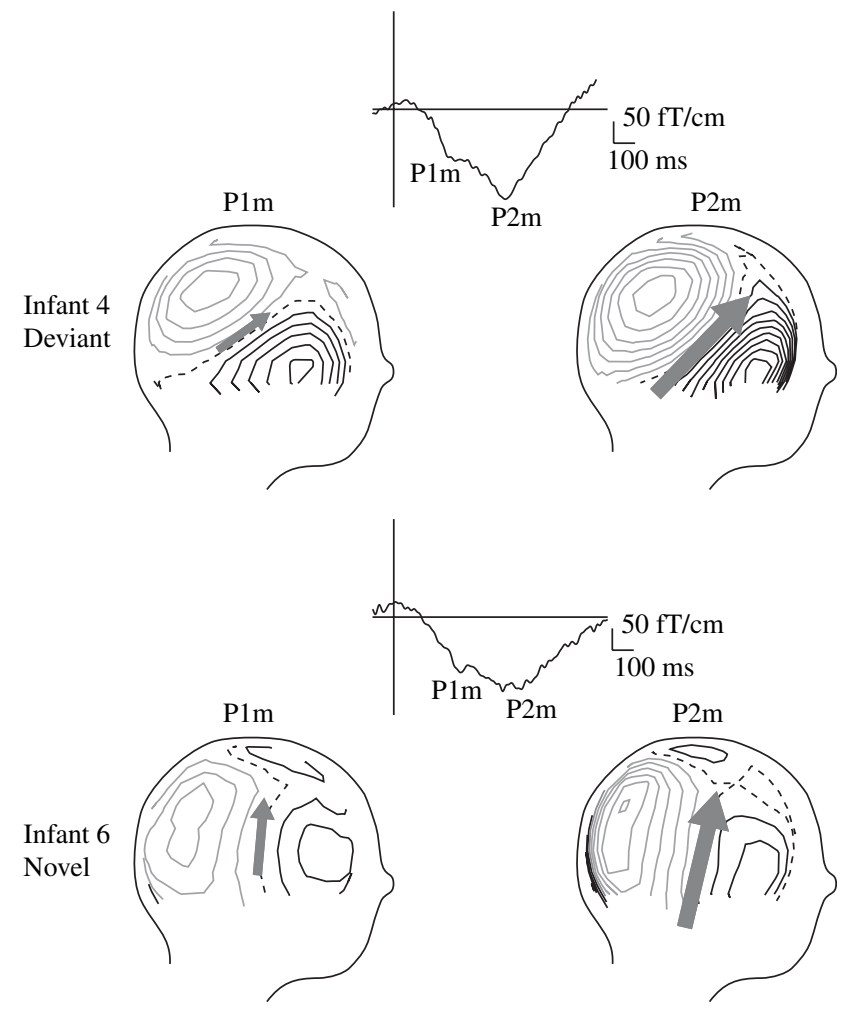

Fig. 4. Field distributions for the two deflections of the deviant response in infant 4 and the novel response in infant 6 , with a contour step of $100 \mathrm{fT}$. It can be seen from the direction of the arrow, depicting the direction of the neural currents, that the responses recorded with ERPs would appear positive in polarity at the frontal and central electrodes.

\section{Discussion}

This study demonstrated that newborns respond stronger to novel than to deviant stimuli, as was shown by the increased responses to the novels compared to deviants for the first deflection. The second deflection, however, did not reveal such an effect as manifested in equally large amplitudes elicited by deviants and novels.

A magnetic counterpart has been found to the negative MMN-like response in neonates when using frequency deviants (Huotilainen et al., 2003). This deflection was localized in or close to the auditory cortex, in which the adult MMN is also partly generated (e.g. Hari et al., 1984; Paavilainen et al., 2003; Rinne et al., 2000). Kujala et al. (2004) replicated this finding using speech stimuli. In the

Table 1

Mean amplitudes (fT/cm) with standard error (in parenthesis) of the vector sums of deflections $\mathrm{P} 1 \mathrm{~m}$ and $\mathrm{P} 2 \mathrm{~m}$ in response to auditory stimulation for the standard, deviant, and novel stimuli

\begin{tabular}{lll}
\hline & $\mathrm{P} 1 \mathrm{~m}(\mathrm{fT} / \mathrm{cm})$ & $\mathrm{P} 2 \mathrm{~m}(\mathrm{fT} / \mathrm{cm})$ \\
\hline Standard & $22.3(3.0)$ & $20.9(3.0)$ \\
Deviant & $47.2(7.5)$ & $57.5(13.6)$ \\
Novel & $71.3(10.3)$ & $65.0(13.0)$ \\
\hline
\end{tabular}


present study, we were not able to accurately locate the two deflections in all subjects, even though several cases (e.g. those seen in Fig. 4) suggested origin in the right temporal lobe. However, from the field distributions, even with nonsuccessful dipole fitting, we could verify that the mismatch response was vertex-positive rather than negative. Several factors including maturational, data-analysis-related, and paradigm-related issues, can account for this polarity difference (Leppänen et al., 2004).

In healthy newborns, the MMN-like component appears with a latency of about 200-300 ms (e.g. Cheour et al., 2002b; Huotilainen et al., 2003; Kushnerenko et al., 2002a). In the present study, however, the first deflection showing the discriminative effect occurred only at around $350 \mathrm{~ms}$ after stimulus onset. Possibly the deflection reached a maximal amplitude later because we used rather long stimulus durations compared with the other studies (300 vs. $100 \mathrm{~ms}$ ). The temporal extension of the response to longer syllables in contrast to shorter ones was reported also by Friedrich in 2-month-old babies (Friedrich et al., 2004). Therefore, it is likely that this deflection reflects the same change-detection process, giving rise to a vertex-positive mismatch response in newborns.

The LDN is a second deflection sometimes found in newborn studies (e.g. Čeponiene et al., 2002; Kushnerenko et al., 2002a; Martynova et al., 2003), but more often in children (for a review, see Cheour et al., 2001). The LDN seems to decrease with age (Cheour et al., 2001). In newborns, it occurs around $300-750 \mathrm{~ms}$ after stimulus onset. So far, the functional significance of this component is not known. Since the second deflection in this study was of positive polarity, the typical LDN was possibly not present in the current study. However, other studies finding a LDN in newborns also showed a negative mismatch response, the MMN (Kushnerenko et al., 2002a; Martynova et al., 2003). In the current study, we showed a positive mismatch response and a positive second deflection. The second deflection $\mathrm{P} 2 \mathrm{~m}$ could possibly be a late discriminative positivity and reflect the same processes as the usually obtained LDN. The LDN has been shown to be larger to novel than to deviant stimuli when presenting a regular oddball task and one in which the deviants were replaced by a novel stimulus (Kushnerenko et al., 2002a). The P2m in our study, however, did not differ between novels and deviants. Either the differences in the paradigms account for this effect, since the novels and deviants were not presented within one session, or the $\mathrm{P} 2 \mathrm{~m}$ does not reflect a late discriminative positivity.

The filter settings may affect the neonatal evoked response data. Most frequently, the infant data have been offline filtered with a $1-\mathrm{Hz}$ high-pass filter (e.g. Čeponiene et al., 2002; Cheour et al., 2002a; Huotilainen et al., 2003; Kushnerenko et al., 2002a,b; Martynova et al., 2003). Cheour et al., (1998) noted the importance of using no offline high-pass filtering in premature-born infants data due to slow waves in their EEG. The high-pass filter setting used during the recordings was $0.03 \mathrm{~Hz}$. While a $0.5 \mathrm{~Hz}$-filter did not noticeably change the responses within the $1 \mathrm{~s}$ epoch, a $1 \mathrm{~Hz}$ filter did so. Thus, also mature newborns have waves slower than $1 \mathrm{~Hz}$ in their evoked brain activity and, consequently, we chose not to use a high-pass filter on the present data. Filtering is, thus, one difference between our study and those of many others and may have affected latency and/or polarity of the responses.

Another possible explanation for our P2m comes from the study of Kushnerenko et al., (2002a). They presented to six healthy newborns a regular oddball task and a task in which the deviant stimuli were replaced by novel stimuli. Enlarged positive responses were found to the novel stimuli compared to the deviants. It was suggested that this response may reflect a neonate analogue of the adult P3a component (Kushnerenko et al., 2002a), which mirrors an orienting response (Picton, 1992). A positive deflection was also found comparing 10-month old infants and young adults in a timing oddball task (Brannon et al., 2004). The positivity peaked around $400 \mathrm{~ms}$ in infants and only at $650 \mathrm{~ms}$ in adults. The deflection in adults was far too late to be the frequently found P3a component. Therefore, they proposed that the infant deflection may not be an analogue of the adult $\mathrm{P} 3 \mathrm{a}$ and may rather reflect a totally different process.

Similarly to our task, Määttä et al., (2005) tested 9-year old children and young adults on a three-stimulus oddball paradigm during a condition where participants had to press a button in response to the deviant, but not to the standard or novel stimuli. Both children and adults showed a P3a component in response to the novels, but not to the deviant stimuli. The same result was found in a study using a passive three-stimulus oddball task in 11-year old children (Čeponiene et al., 2004). A P3a was present in response to the novels, but not to the deviants. The P2m found in the present study was equally large to the deviant and novel stimuli. Either this deflection does not reflect the P3a component, or it is still immature, since it should not have been present at all to the deviants.

Some neonatal studies using consonant-vowel syllables as stimuli show a bi-lobed response waveform as found in most newborns in the present study (Leppänen et al., 1999; Pihko et al., 2004). In a study in which the stimuli were syllables composed of a fricative and a vowel, it was suggested that the second deflection may reflect the change from the fricative to the vowel (Pihko et al., 2004). This, however, cannot be the case in the present study, since our stimuli were very different. One additional option is that our second deflection is a response to the offset of the stimulus, since we had rather long stimulus durations. Though the latency of the second response is reasonable to reflect the offset, Kushnerenko et al., (2001) did not see offset responses of the same latency as the $\mathrm{P} 2 \mathrm{~m}$ in our study when they presented tones of different durations, their longest one even being longer than our stimuli. The most likely option is that the second deflection indeed reflects some late cognitive process. More studies are needed to 
reveal the functional significance of this deflection. Regardless of which component or process the second deflection of our study reflects, a late discriminative positivity, the $\mathrm{P} 3 \mathrm{a}$, or another late process, this deflection showed the immaturity of some part of the auditory system at birth. After all, the responses to deviant and novel stimuli did not significantly differ, although they do in children (Čeponiene et al., 2004).

In the ideal case, the infant is sleeping quietly without moving his or her head in the measurement device long enough to successfully perform a MEG measurement, in this case, for obtaining a robust enough auditory evoked response with a sufficient number of trials in the average for a reasonable signal to noise ratio. In such a case, MEG is superior in locating the underlying activity compared to the evoked potentials measured with just a few electrodes as in most neonatal studies. In addition, being sensitive mostly to currents tangentially oriented relative to the head surface, MEG is ideal in selectively measuring the activity from auditory areas imbedded in the temporal sulci. The data in the present study, however, did not allow us to successfully calculate the equivalent current dipoles for the activities for all subjects e.g. due to small responses or relatively low number or trials in the average, the responses thus including some 'noise' from the background high-voltage activity in quiet sleep. Another advantage of neonatal MEG above EEG studies is that it may further be useful in supporting the understanding of fetal MEG-data (Huotilainen et al., 2005).

In conclusion, we have shown that change detection is stronger to novel than to deviant stimuli already in newborns, suggesting that the auditory detection mechanism is relatively mature at birth.

\section{Acknowledgements}

This study was supported by the Centre for International Mobility (CIMO) of Finland and the Academy of Finland. We thank research nurse Suvi Heikkilä for kindly helping us in taking care of the newborns.

\section{References}

Alho K, Sainio K, Sajaniemi N, Reinikainen K, Näätänen R. Event-related potential of humans to pitch change of an acoustic stimulus. Electroencephalogr Clin Neurophysiol 1990;77:151-5.

Alho K, Winkler I, Escera C, Huotilainen M, Virtanen J, Jaaskelainen IP, Pekkonen E, Ilmoniemi RJ. Processing of novel sounds and frequency changes in the human auditory cortex: magnetoencephalographic recordings. Psychophysiology 1998;35:211-24.

Brannon EM, Wolfe Roussel L, Meck WH, Woldorff M. Timing in the baby brain. Cogn Brain Res 2004;21:227-33.

Čeponiene R, Cheour M, Näätänen R. Interstimulus interval and auditory event-related potentials in children: evidence for multiple generators. Electroencephalogr Clin Neurophysiol 1998;108:345-54.
Čeponiene R, Kushnerenko E, Fellman V, Renlund M, Suominen K, Näätänen R. Event-related potential features indexing central auditory discrimination by newborns. Cogn Brain Res 2002;13:101-13.

Čeponiene R, Lepistö T, Soininen M, Aronen E, Alku P, Näätänen R. Event-related potentials associated with sound discrimination versus novelty detection in children. Psychophysiology 2004;41:130-41.

Cheour M, Alho K, Čeponiene R, Reinikainen K, Sainio K, Phjavuori M, Aaltonen $\mathrm{O}$, Näätänen R. Maturation of mismatch negativity in infants. Int J Psychophysiol 1998;29:217-26.

Cheour M, Korpilahti P, Martynova O, Lang A-H. Mismatch negativity and late discriminative negativity in investigating speech perception and learning in children and infants. Audiol Neurootol 2001;6:2-11.

Cheour M, Kushnerenko E, Čeponiene R, Fellman V, Näätänen R. Electric brain responses obtained from newborn infants to changes in duration in complex harmonic tones. Dev Neuropsychol 2002a;22:471-9.

Cheour M, Martynova O, Näätänen R, Erkola R, Sillanpää M, Kero P, Raz A, Kaipio M-L, Hiltunen J, Aaltonen O, Savela J, Hämäläinen H. Speech sounds learned by sleeping newborns. Nature 2002b;45: 599-600

Cheour M, Imada $\mathrm{T}$, Taulu S, Ahonen A, Salonen J, Kuhl P. Magnetoencephalography is feasible for infant assessment of auditory discrimination. Exp Neurol 2004;190:S44-S51.

Csepe V, Karmos G, Molnar M. Evoked potential correlates of stimulus deviance during wakefulness and sleep in cat-animal model of mismatch negativity. Electroencephalogr Clin Neurophysiol 1987;66: $571-8$.

Donchin E. Surprise!...surprise? Psychophysiology 1981;18:493-513.

Ellingson RJ, Danahy T, Nelson B, Lathrop GH. Variability of auditory evoked potentials in human newborns. Electroencephalogr Clin Neurophysiol 1974;36:155-62.

Escera C, Alho K, Winkler I, Näätänen R. Neural mechanisms of involuntary attention to acoustic novelty and change. J Cogn Neurosci 1998;10:590-604.

Friedrich M, Weber C, Friederici AD. Electrophysiological evidence for delayed mismatch response in infants at-risk for specific language impairment. Psychophysiology 2004;41:772-82.

Hari R, Hämäläinen M, Ilmoniemi R, Kaukoranta E, Reinikainen K, Salminen J, Alho K, Näätänen R, Sams M. Responses of the primary auditory cortex to pitch changes in a sequence of tone pips: neuromagnetic recordings in man. Neurosci Lett 1984;50:127-32.

Huotilainen M, Kujala A, Hotakainen M, Shestakova A, Kushnerenko E, Parkkonen L, Fellman V, Näätänen R. Auditory magnetic responses of healthy newborns. NeuroReport 2003;14:1871-3.

Huotilainen M, Kujala A, Hotakainen M, Parkkonen L, Taulu S, Simola J, Nenonen J, Karjalainen M, Näätänen R. Short-term memory functions of the human fetus recorded with magnetoencephalography. NeuroReport 2005;16:81-4

Javitt DC, Schroeder CE, Steinschneider M, Arezzo JC, Vaughan Jr HG. Demonstration of mismatch negativity in the monkey. Electroencephalogr Clin Neurophysiol 1992;83:87-90.

Kok A. On the utility of $\mathrm{P} 3$ amplitude as a measure of processing capacity. Psychophysiology 2002;38:557-77.

Kujala A, Huotilainen M, Hotakainen M, Lennes M, Parkkonen L, Fellman V, Näätänen R. Speech-sound discrimination in neonates as measured with MEG. NeuroReport 2004;15:2089-92.

Kurtzberg D, Hilpert PL, Kreuzer JA, Vaughan Jr HG. Differential maturation of cortical auditory evoked potentials to speech sounds in normal fullterm and very low-birth weight infants. Dev Med Child Neurol 1984;26:466-75.

Kushnerenko E, Čeponiene R, Fellman V, Huotilainen M, Winkler I. Event-related potential correlates of sound duration: similar pattern from birth to adulthood. NeuroReport 2001;12:3777-81.

Kushnerenko E, Čeponiene R, Balan P, Fellman V, Näätänen R. Maturation of the auditory change detection response in infants: a longitudinal ERP study. NeuroReport 2002a;13:1843-8. 
Kushnerenko E, Čeponiene R, Balan P, Fellman V, Huotilainen M, Näätänen R. Maturation of the auditory event-related potentials during the first year of life. NeuroReport 2002b;13:47-51.

Lengle JM, Chen M, Wakai RT. Improved neuromagnetic detection of tefal and neonatal auditory evoked responses. Clin Neurophysiol 2001;112: 785-92.

Leppänen PHT, Eklund KM, Lyytinen H. Event-related brain potentials to change in rapidly presented acoustic stimuli in newborns. Dev Neuropsychol 1997;13:175-204.

Leppänen PHT, Pihko E, Eklund KM, Lyytinen H. Cortical responses of infants with and without a genetic risk for dyslexia: II. Group effects. NeuroReport 1999;10:969-73.

Leppänen PHT, Guttorm TK, Pihko E, Takkinen S, Eklund KM, Lyytinen H. Maturational effects on newborns ERPs measured in the mismatch negativity paradigm. Exp Neurol 2004;190:S91-S101.

Määttä S, Pääkkönen A, Saavalainen P, Partanen J. Selective attention event-related potential effects from auditory novel stimuli in children and adults. Clin Neurophysiol 2005;116:129-41.

Martynova O, Kirjavainen J, Cheour M. Mismatch negativity and late discriminative negativity in sleeping human newborns. Neurosci Lett 2003;340:75-8.

McIsaac H, Polich J. Comparison of infant and adult P300 from auditory stimuli. J Exp Child Psychol 1992;53:115-28.

Näätänen R, Winkler I. The concept of auditory stimulus representation in cognitive neuroscience. Psychol Bull 1999;826-59.
Novak GP, Kurtzberg D, Kreuzer JA, Vaughan Jr HG. Cortical responses to speech sounds and their formants in normal infants: maturational sequence and spatiotemporal analysis. Electroencephalogr Clin Neurophysiol 1989;73:295-305.

Ohlrich ES, Barnet AB. Auditory evoked responses during the first year of life. Electroencephalogr Clin Neurophysiol 1972;32:161-9.

Paavilainen P, Mikkonen M, Kilpeläinen M, Lehtinen R, Saarela M, Tapola L. Evidence for the different additivity of the temporal and frontal generators of mismatch negativity: a human auditory eventrelated potential study. Neurosci Lett 2003;349:79-82.

Picton T. The P300 wave of the human event-related potential. J Clin Neurophysiol 1992;9:456-79.

Pihko E, Sambeth A, Leppänen P, Okada Y, Lauronen L. Auditory evoked magnetic fields to speech stimulus in newborns-effect of sleep stages. Neurol Clin Neurophysiol 2004;6:1-5.

Rinne T, Alho K, Ilmoniemi R, Virtanen J, Näätänen R. Separate time behaviors of the temporal and frontal mismatch negativity sources. Neuroimage 2000;12:14-19.

Ruusuvirta T, Penttonen M, Korhonen T. Auditory cortical event-related potentials to pitch deviances in rats. NeuroReport 1998;248:45-8.

Shestakova A, Huotilainen M, Čeponiene R, Cheour M. Event-related potentials associated with second language learning in children. Clin Neurophysiol 2003;114:1507-12.

Taulu S, Kajola M, Simola J. Suppression of interference and artifacts by the signal space separation method. Brain Topogr 2004;16:269-75. 